\title{
A virtual reality-based language learning environment to teach sentence word order
}

\author{
Kanade Sato ${ }^{1 *}$, Kazuhiko Hamamoto ${ }^{2}$, David Wright ${ }^{3}$, Hiroshi Nakagawa ${ }^{4}$ \\ 1, 2, 3, 4 Tokai University, Tokyo, Japan
}

\author{
Keywords \\ VR \\ Sentence word order \\ Technology Enhanced Learning \\ (TEL) \\ Linguistics
}

Received: 7 August 2019

Accepted: 4 September 2019

Published: 31 October 2019

\begin{abstract}
As part of a larger interdisciplinary research project, the objective of this small-scale study is to develop an engaging Virtual Reality (VR) based language learning task focused on sentence word order. It builds on a previous study of a VR-based language activity targeting prepositions. This study focused on providing an engaging language learning experience through immersive visual effects and tactile feedback from interactive 3D worlds. Furthermore, a new standalone HMD system that allowed users to walk freely around the VR space was procured for the study. University students $(n=17)$ each completed five sentences during a single treatment session. A 28 question exit survey was conducted immediately after the experiment. Analysis of the results showed that 11 out of 17 subjects felt the operation of the VR task was intuitive. Subjects found the learning tasks were monotonous. In addition, some found it difficult to move around the VR space using handheld VR controllers while wearing a wired Head Mounted Display (HMD). In addition, all subjects stated that compared to traditional language-learning activities, they enjoyed doing the activity. However, a review of the subjects' behaviors, captured by a video camera, indicated that some subjects were initially confused about physically manipulating the words. Based on the study results presented here, the VR-based language activity was found to be a pleasurable way to study sentence word order. Future goals include the creation of interactive tutorials and a larger set of content.
\end{abstract}

(C) 2019 The Author(s). Published by TAF Publishing

\section{INTRODUCTION}

\section{Statement of the Problem}

In recent years, the Government of Japan has started promoting the development of global human resources in order to adapt to social and economic globalization. The Second Basic Plan for the Promotion of Education defined the national education policies for traditional students and also for people in each life stage was adopted in Japan (Ministry of Education, Culture, Sports, Science and Technology, 2013; Thiangthung, 2016). One of the policies referred to the enhancement of foreign language education including a focus on English language skills. In Japan, the compulsory education system is composed of a six-year elementary school and a three-year junior high school period. In the past, first year junior high school students started learning English at school. However, from 2020 onwards,
English will be an official subject for 5 th and 6th grade elementary school students. The government policy is meant to encourage future workers to study a diverse set of global languages.

On the other hand, previous attempts by the Japanese government to reform the education system have been lacking. In fact, many Japanese people feel they are not good at communicating in English. According to a survey conducted by the Benesse Educational Research and Development Institute (2018) 48.4\% of the 3rd year junior high school students in Japan answered that they were bad or slightly bad at English. In addition, another survey (The Institute for International Business Communication, 2019) targeted at working adults in Japan showed that $69.0 \%$ of them felt they were bad or relatively bad at English. Those two surveys indicate that a certain amount of Japanese people already

\footnotetext{
${ }^{*}$ corresponding author: Kanade Sato

†email: k.sato@hope.tokai-u.jp
} 
have a low level of confidence in their English abilities starting when they were junior high school students, and that cohort of people grew for working adults despite prior education reforms.

On the other hand, public interest in the socio-economic value of English is growing. The reason is not only the effects of the new educational policy, but also an increase of international visitors to Japan. For instance, the results of a report conducted by the Japan National Tourism Organization (JNTO) in 2020, as Figure 1 shows, indicate the number of people visiting Japan in recent years has increased year on year. Furthermore, Japan will host the Tokyo Olympics Games in the summer of 2021, and there is a possibility that many international visitors will visit the county to watch the games. Although a large portion of native Japanese speakers have limited need to speak English at work or school, they may need to communicate in English in their daily lives as they are more likely to interact with a diverse sociolinguistic group. The above factors are part of the reason the Japanese government is seeking to reform the education system.

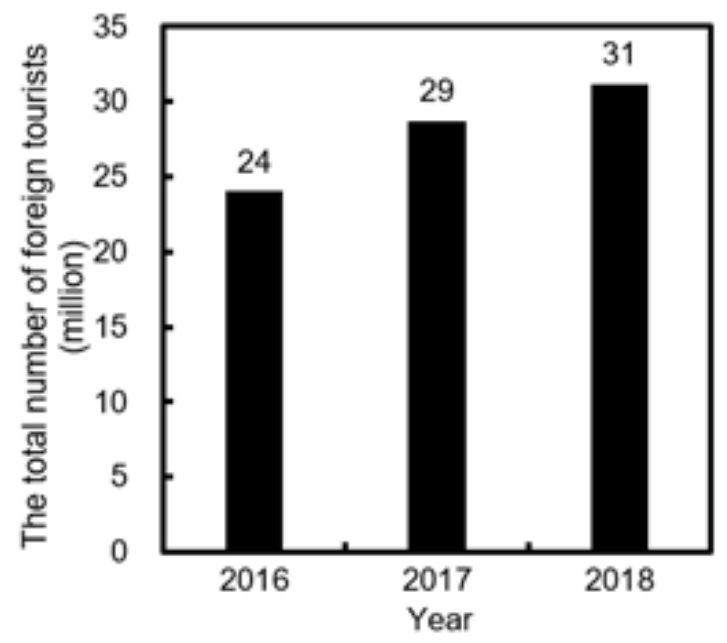

FIGURE 1. Changes of the total number of foreign tourists visiting Japan

VR

VR is a technology, that in addition to being used for entertainment, is also used in safety training courses in the medical and industries. One primary advantage is the capability to faithfully reproduce the environment like the corresponding version of reality. This is achieved through immersive cues, such as visuals referents, that allow a participant to feel as if they gave entered the VR space. Going further, tactile and aural information are synchronized with the visual information. As costs have come down, in recent years, educational materials using VR have also been devel- oped.

\section{Sentence Word Order Activity}

A language activity where a student places a set of words into a specific order to create a sentence that is (at a minimum) grammatically correct.

\section{Problem}

To successfully adapt to ever increasing globalization, it's safe to say that English is no longer a dispensable language for Japanese people. However, the Swiss international education company, Education First (2019) that Japan's English proficiency rank was 53 out of 100 non-English speaking countries and regions. The company categorized Japan as in the low proficiency group. Therefore, Japanese people need to overcome their apprehension to speaking in English to promote internationalization.

\section{Objectives (Goals)}

1) To increase learner motivation to communicate in English and provide an opportunity to learn practical English in real-world settings.

2) To develop enjoyable and successive learning experience through activities that continuously engage learners during repetitive exercises. This will help students to keep studying while they overcome their weaknesses in their English language ability.

3) To leverage technology in language education in order to provide new ways to learn and increase learner's motivation, particularly with immersive computer simulations.

\section{Significance of the Study}

The Government of Japan is working on education reform and has promoted the leveraging Information Technology to improve traditional school education. Ministory of Education, Culture, Sports, Science and Technology (2014) reported the results of an empirical study aimed to investigate the effects of technology (e.g., digital textbooks, interactive blackboards) on elementary school and junior high school education. The report stated that "picture and video materials helped students to better understand class content, and students' motivation for learning was increasing" (pp. 9-10). However, the report also referred to the following considerations:

a) In terms of learning materials, students need to not only use digital materials but also study through experiential learning.

b) students need to not only learn how to pronounce a word or make conversation through digital materials, but also need to experience face-to-face communication exer- 
cises with classmates, instructors or native English speakers. From the results of the empirical study, the use of digital materials in class is expected to increase students' motivation for learning and to have positive effects for school education. However, the study also found that there are not enough digital learning materials to provide experiential or communicative learning activities.

In the study presented here, VR teaching content is leveraged for use in English language learning. The emerging technology which enables users to interact with content within 3D worlds is expected to provide immersive and realistic experiences. VR has the potential to address many of the problems with current digital learning materials such as a lack of experiential learning activities and engaging students more by virtually placing them in learning experiences that are also interactive language activities.

\section{Scope of the Study}

This study focused on developing a VR application to provide an enjoyable way to complete an English grammar activity while simultaneously promoting autonomous learning. To create such a learning activity aimed to teach English grammar, a sentence word order activity was modified for the VR application. After making a working prototype of the application, a survey was conducted on university students in Japan to investigate the following questions: a) Was the application enjoyable to the participants and did it provide successive learning experiences for the users and b) Was the operation of the application comfortable for uses, in terms of the User Interface (UI). In particular, it was important to investigate the operability of the VR application. The UI between VR content and users was unique because it required participants to use VR controllers as extensions of their real-world hands and arms and in addition to move around the VR space by physically walking across an open space. In comparison, during a traditional digital activity, participants would be touching on screen (i.e., a tablet computer) or manipulating a mouse and keyboard (i.e., on a desktop computer). In the survey, the following three data sets were collected from the participants: a) 28-question questionnaire, b) a gameplay video which recorded the subjects performance within the VR activity, c) a video which recorded subject's behavior in real space as the moved around a specially prepared space.

\section{LITERATURE REVIEW}

\section{VR in Education}

A study which was conducted on 40 high school students in Beijing, China (Beijing Bluefocus E-Commerce, 2016; Taher,
Shrestha, Rahman, \& Khalid, 2016) reported that "By triggering students' interest towards learning, VR makes students more willing to learn. What's more, VR-based teaching could make students more attentive, more easily absorb content knowledge, and finally to improve their test scores" (p. 10). The students were divided into four groups, and all of them studied and took an exam about celestial physics during the experiments. First two groups participated in an experiment to compare the impact of VR-based learning and traditional PowerPoint-based learning on their test score. Each group learned the content in different methods (VRbased or PowerPoint-based learning) , then they immediately took a test to measure their understanding of subject matter content. As a result, the average posttest score of the VR-based group was higher than the score of the students who studied by the traditional (e.g., PowerPoint) learning method. In addition, another two groups took a delayed posttest exam two weeks after the treatments to investigate their memory retention. The result of the average delayed posttest score showed that the score of the VR-based group was also higher than the score of the students who studied the same content using PowerPoint slides. The report also asked the students who were in the two different VR-based learning groups to reveal the students' attitudes towards VR. It found "95\% students are willing to recommend VR to others in their learning (p.18)." Based on the case study, VR can be an effective way to improve both students' attitudes towards learning and students' academic performance on subject matter content.

\section{Computer Mediated Activities}

In terms of the impact of UI designs for word order practice using computers, research has found that "drag-and-drop was significantly more effective than multiple choice exercises and similar to text completion" (Heift, 2003; Junnak \& Veerachaisantikul, 2016).

\section{Technology Enhanced Learning (TEL)}

Pardo-Ballester (2019) found that first-person, desktop computer-based activities can simultaneously assist with language development and subject matter knowledge.

\section{Previous Studies}

In a previous study related to this project (Nakano \& Wright, 2019), a VR-based English language learning activity which focused on learning prepositions of location through collaborative tasks was designed to teach English grammar. There were the following two different roles in the learning activity: (a) student (maximum number for the role: two students) and an (b) instructor. The flow of the activity is the 
following:

1) Each player wears a HMD, also known as VR headset, and is placed in different rooms in a VR space.

2) The person in the instructor role gives pre-recorded voice instructions in English by pushing a button in the room.

3) The participant(s) in the student role follows the instruction and places objects (e.g. food, tableware, etc.) in the correct place to complete the learning task.

4) The instructor can monitor the student (s) behavior in real-time during the learning activity.

5) Upon completing, the student (s) and the instructor can review their performance.

After developing the VR-based English learning activity, a pilot test was conducted. From the result of the tests, participants said the learning tasks were monotonous for their level ability. In addition, some students found it difficult to move around the VR space using handheld VR controllers while wearing a wired HMD, as movement across the space was done using a stick on the handheld controller. The current study builds on the work by Nakano and Wright (2019) by developing a more user-friendly UI and creating a more level appropriate language activity. With that in mind, the following research questions were created.

\section{Research Questions}

1) Will students' motivation to learn English grammar improve during the VR activity?

2) Do sound effects or visual and tactile feedback provide a more enjoyable learning experience?

3) Will a UI that allows participants to literally walking freely around the VR space shorten the familiarization process?

\section{RESEARCH METHODOLOGY}

This study was divided into two phases. In the first phase, we developed the VR-based word order activity. In the second phase we conducted a test of a working prototype test using the VR-based activity.

\section{The Concept of the VR-Based Word Order Activity}

The concept of the VR-based word order activity essentially follows a paper-based or computer-based word order activity. In other words, a student is given a scrambled sentence and is tasked with putting the words in the correct order to complete the exercise. However, the VR-based word order learning application has the following unique characteristics:

a) The students can physically interact with words (e.g., literally touch, grab, and even throw a word).

b) The VR application provides sound effects as well as visual and tactile feedback which links with the students' behaviors and or answers (e.g., VR controllers vibrate when a player touches a word.).

c) The students can literally walk freely around the VR space using a standalone HMD.

d) Sentences for the word order activity can be changed and the individual words are placed in a VR space randomly so that the students can keep learning various and new contents.

e) The application checks the student's answers automatically.

Those characteristics were influenced by the areas of improvement identified in a previous study, especially points c) and d). In contrast to the prior study, the word order activity has been initially designed for a single player.

\section{The Flow of the VR-Based Word Order Activity}

The flow of the learning activity is the following:

1) A player, wearing and HMD, is placed in a room with the words from a sentence scrambled and place around the room.

2) The player walks around the VR space to find a target word.

3) The player grabs each word and puts it on an answer field, attempting to place the words in the correct order using the VR controllers.

4) Upon completing a sentence, the application checks the answer automatically and displays different audio-visual effects depending on the result.

5) The player Repeats from 1) through 4) five times.

6) After completing five sentences, the player can check the commulative result from Sentence 1 (Q1) through Sentence 5 (Q5).

\section{Development Environment}

The development Environment for the word order activity is shown in Table 1. An Oculus Quest (shown in Figure 2) was selected as it provides a standalone VR experience with integrated HMD and VR controllers. To develop the VR application, Unity 2019.1.2 f was chosen given that Oculus recommends it for use with VR applications. 
TABLE 1. Development environment

\begin{tabular}{lllll}
\hline \hline Equipment & Product Name & OS & CPU/Version & Purpose \\
\hline Laptop & HP Spectre 13 & Windows 10 pro & intel@ Core ${ }^{\mathrm{TM}}$ i7-8550U & To use Unity \\
Standalone HMD & Oculus Quest & Android & 13.0 or lower & To use the VR activity \\
Software for VR development & Unity for Windows & Android Platform & $2019.1 .2 \mathrm{f}$ & To develop the VR activity \\
\hline \hline
\end{tabular}

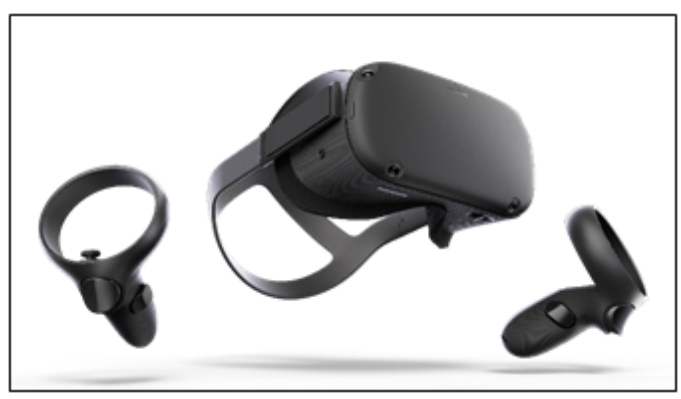

FIGURE 2. Oculus quest (HMD and the VR controllers) Source: https://bit.ly/2MmgIZ0

In addition, Table 2 shows a list of Unity assets used to develop the application. To display the VR application in Ocu- lus Quest's HMD, the "Oculus Camera Rig" prefab in Oculus Integration is needed instead of default Unity Camera. VR Toolkit provides various scripts, also known as components in Unity to create VR applications, such as a component for implementing interactions like touching, grabbing objects, and virtual pointers. In particular, "Snap Drop Zone" component is an effective way to create answer fields (i.e., containers for each word in the sentence) in the VR space. The component provides predefined zone to drop an Object. In addition, FlyingText3D is used to create 3D word Objects which follow physics and allow users to touch or grab the words as well as other game Objects in Unity3D.

TABLE 2. Unity assets

\begin{tabular}{llll}
\hline \hline Asset Name & Version & Key Component/Prefab & Purpose \\
\hline Oculus Integration & 1.37 .0 & Prefab: Oculus Camera Rig & To display the VR activity in Oculus Quest's HMD \\
Virtual Reality Toolkit & 3.3 .0 & Component: Snap Drop Zone & To implement VR interaction \\
Flying Text 3D & 2.2 .1 & Component: Flying Text & To generate 3D words \\
\hline \hline
\end{tabular}

\section{The Design of the Answer Fields}

As mentioned in the Development Environment section, the answer fields of this VR-based word order activity were created with "Snap Drop Zone" component, which provides predefined zones to drop an Objects in the VR space. Each answer field is created as a 3D Object which is shaped as a number. In addition, the snap drop zone component is attached to each number shaped object. The numbers indicate the order of the words in the sentence. When the user drops a word near the number shaped object, the word is fixed to the object. The word can demount from the answer field when the player grabs the word again.

\section{The Algorithm to Automatically Check the Answer}

The answer check system employs a tag feature which can identify an object in Unity. The following is the flow of the system:

1) Each answer field is given a tag which is named after its corresponding number;

2) Each word is given a tag which indicates the correct position (i.e., order) in a sentence;

3) The answer field returns a "True" flag when a word is fixed to it;

4) When all the answer fields return "True" flags, the system starts comparing the tag of each answer field to the tag of each word (i.e., the correct answer);

5) When the tag of each answer field matches the tag of each word, the answer is correct.

6) If the answer is correct, the message "correct" appears with corresponding sounds and visual effects in the VR Space;

7) If the answer is incorrect, the message "wrong..." appears with appropriate sounds and visual effects in the VR Space.

\section{Load Sentences from a CSV File}

Sentences for the word order activity can be input, changed, and edited by loading a specifically formatted CSV file. The application automatically creates 3D word objects by reading the CSV file. In this way, Instructors are not required to change parameters (e.g., have technical skills) in Unity Editor.

\section{Working Prototype Test: Objectives \& Subjects}

The objectives of this study were the following:

a) Is the learning activity enjoyable while providing a successive learning experience (e.g., scaffolded learning) for users?

b) Is the UI system easy-to-use for users without the need for excessive training? 
TABLE 3. The subjects by academic

\begin{tabular}{lll}
\multicolumn{3}{c}{ year and gender } \\
\hline \hline Academic Year & Male & Female \\
\hline 1st year & 4 & 3 \\
2nd year & 0 & 2 \\
3rd year & 4 & 2 \\
4th year & 1 & 5 \\
Total & 9 & 12 \\
\hline \hline
\end{tabular}

The primary target of the learning activity was University students studying a foreign language. In this study, 21 University students from a university in Tokyo, Japan participated in this test. Table 3 shows a detailed description of the subjects by academic year and gender.

\section{Working Prototype Test: Data Collection}

In this test, three different data sets were collected. The data were as follows:

1) a paper-based questionnaire with 28 questions;

2) a gameplay video which recorded the subject's performance within the VR activity;

3) a video which recorded subject's behavior in real space. The questionnaire consisted mostly of 5-point Likert scale questions and an open-ended question. The subjects were required to answer questions related to the following topics:

1) Past experience in VR-environments;

2) The UI of the VR-based learning activity;

3) The user experience of the VR-based learning activity;

4) General attitude towards learning English.

Furthermore, two different video data types were collected. In the test, the VR-based activity was only shown in the HMD, meaning the participants only point of reference was their experience inside the VR space. The recorded gameplay video helped the researchers to understand the participant's performance during the activity. Furthermore, a video which recorded the subject's behavior in real space assisted the researchers in better understanding how the participants reacted to the VR activity, by showing their behavior in real space during the activity.

\section{Working Prototype Test: Experimental Environment \& Procedure}

The test was conducted under the following environmental conditions:

a) an indoor space;

b) VR play area was a 2 meter $\times 2$ meter square.

The VR application was designed for Room scale VR mode, which means the players of the VR application are free to move around a real physical space during the activity. The VR-based activity is expected to be used in a classroom.
Therefore, in this test, the subjects were only allowed to move around a small space, which can be set withing the Oculus Quest and defined as a minimum play area. The play area was created using the Oculus Guardian System. When the subjects stepped out of the play area, they were prevented from using the application for their safety. Next, the procedure to conduct the activity is described as following: 1) Gave verbal instructions on how to complete a sentence using the VR controllers (e.g., how to grab a word);

2) Presented sentences 1 to 5 (shown in Table 4) one by one in the VR space;

3) During the activity, a gameplay video of the subject's performance within the VR activity and a video which recorded subject's behavior in real space were recorded;

4) After completing five sentences, the subject answered a paper-based questionnaire.

TABLE 4. 5 sentences for the VR-based word

\begin{tabular}{ll}
\multicolumn{2}{c}{ activity } \\
\hline \hline Sentence No. & Contents \\
\hline Sentence 1 & The/earth/goes/around/the/sun \\
Sentence 2 & Julia/is/very/good/at/languages \\
Sentence 3 & Rice/doesn't/grow/in/cold/climates \\
Sentence 4 & Where/do/you/come/from/? \\
Sentence 5 & Is/your/English/getting/better/? \\
\hline \hline
\end{tabular}

Content drawn from Raymond Murphy. English Grammar in Use, With answers and eBook, Fourth Edition, A selfstudy reference and practice book for intermediate learners of English, Cambridge University Press (Sentence 1, 3, 4: p. 4, Sentence 2: p. 7, Sentence 5: p. 2)

\section{Working Prototype Test: The Analysis of the Data}

The data analysis focused on the following points:

1) The results of the UI evaluation from the subjects who had only a few experiences with VR.

2) The attitudes of the subjects' who felt they were not good at English in reference to the VR-based learning activity.

To analyze the working prototype test results, we used a Google Form to aggregate the data from the questionnaires. In addition, we played and synchronized the two videos (i.e., VR gameplay and video of participants wearing HMDs) to observe the subjects' behaviors both in the VR space and in real space. 


\section{RESULTS}

\section{VR-based Sentence Word Order Activity}

The procedure for completing a sentence is the same throughout the activity. Therefore, Sentence 1 (Q1) is used as an example to explain the procedure.

Figure 3 shows the perspective of the student within the overall VR space. The individual words were created as 3D word objects by reading the CSV file (shown in Figure 4) and randomly placed on the floor. In order to avoid overlap, the answer fields were alternately arranged upward and downward.

The word "goes" was also placed on the floor, but it was outside of the angle of view presented here.

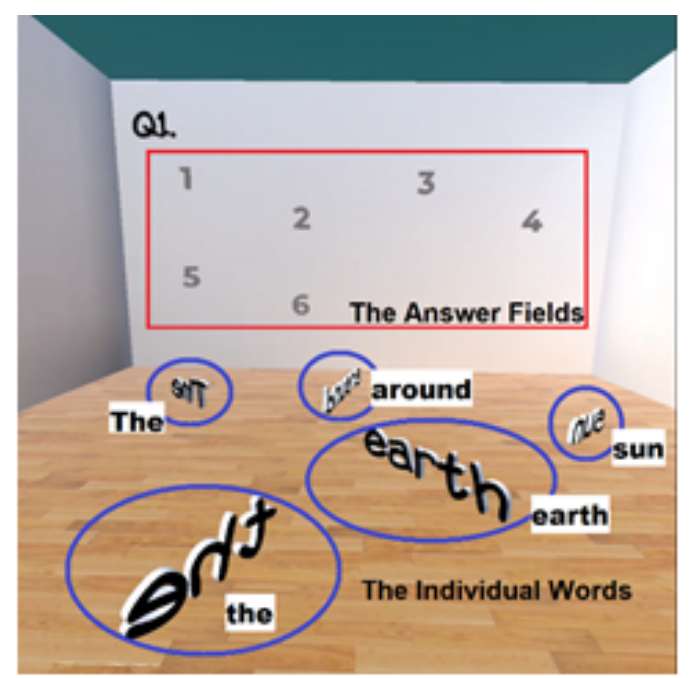

FIGURE 3. The overview of the VR space (from the viewpoint of the player)

\begin{tabular}{|c|c|c|c|c|c|c|c|}
\hline$\Delta$ & A & B & c & D & $\mathrm{E}$ & $F$ & G \\
\hline 1 & tag & word1 & word2 & word3 & word4 & word5 & word6 \\
\hline 2 & Q1 & The & earth & goes & around & the & sun \\
\hline 3 & Q2 & Julla & is & very & good & at & languages \\
\hline 4 & Q3 & Rice & doesn't & grow & in & cold & climates \\
\hline 5 & Q4 & Where & do & you & come & from & ? \\
\hline 6 & Q5 & Is & your & English & getting & better & ? \\
\hline
\end{tabular}

FIGURE 4. The CSV File for the word order activity

As shown in Figure 5, The player was able to grab the words using a virtual hand or using the virtual pointer. In the VR space, the VR controllers were replaced as virtual hands. In

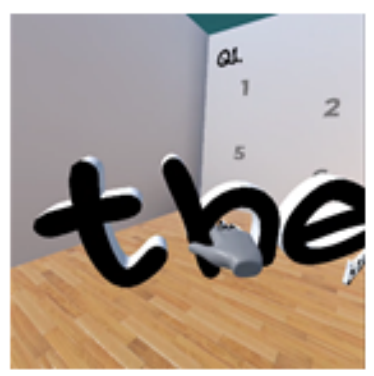

FIGURE 5. How to grab the words

Note: Left image: Grab the word using the virtual hands. Right image: Grab the word using the virtual pointer. Figure 6 describes how to put the word in the answer field. addition, the virtual pointer was emitted if the corresponding button on the right controller was pushed.

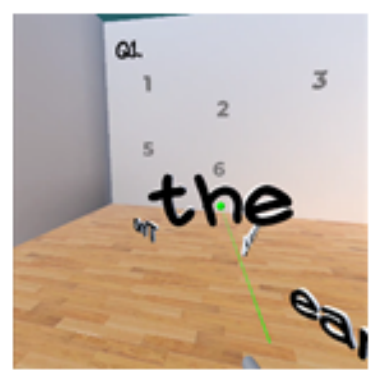

When the word was close enough to the answer fields, it turned green. It meant the word was then fixed to the wall even if the player released the word. 

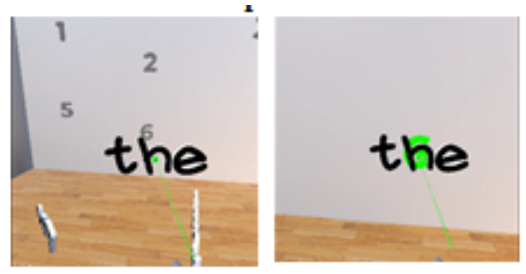

FIGURE 6. How to put the word in the answer field

Note: Left image: the word was not close enough to the answer fields.

Center image: the answer field turned green Right image: the word was fixed to the answer field.

After completing a sentence, the system judged the answer, and the message "correct" or "wrong..." appeared with corresponding sounds and visual effects depending on the result. Figure 7 shows each message and visual effect.
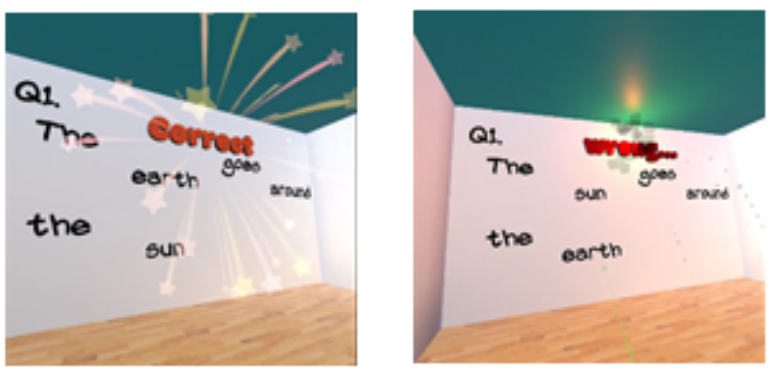

FIGURE 7. The messages and visual effects correspond to the result

Note. Leftimage: A fireworks animation effect and the message "Correct" appears if the answer is correct. Right image: A explosion animation effect and the message "wrong..." appears if the answer is incorrect.

The player is required to go from Q1 to Q5 continuously. After answering Sentence 5 (Q5), the application shows the whole result from Sentence 1 (Q1) through Sentence 5 (Q5) as shown in Figure 8. A correct answer is marked with a green circle and an incorrect answer with a red $\mathrm{X}$.

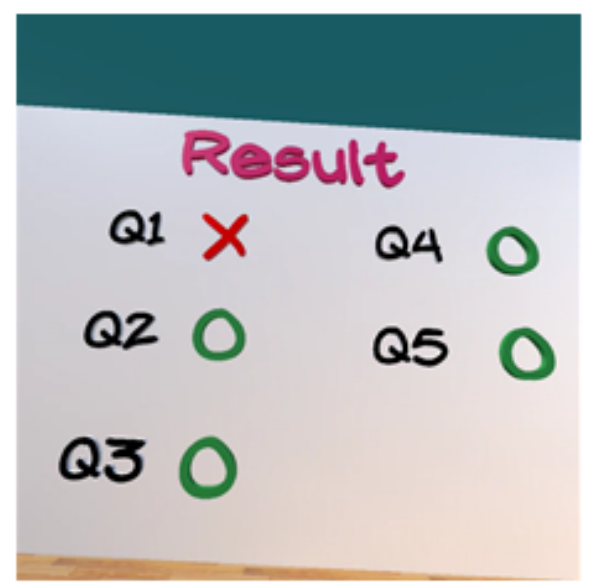

FIGURE 8. Showing the whole result from Q1 to Q5

\section{The Analysis of Working Prototype Test: The Result from the Questionnaire}

We conducted the analysis on 17 valid subjects because the video data for four subjects could not be collected due to unforeseeable circumstances with video recording equipment or the Oculus Quest HMD. Figure 9 shows the subjects' attitude towards learning English. According to the results of the questionnaire, nearly $60 \%$ of participants answered that they felt not good at English.

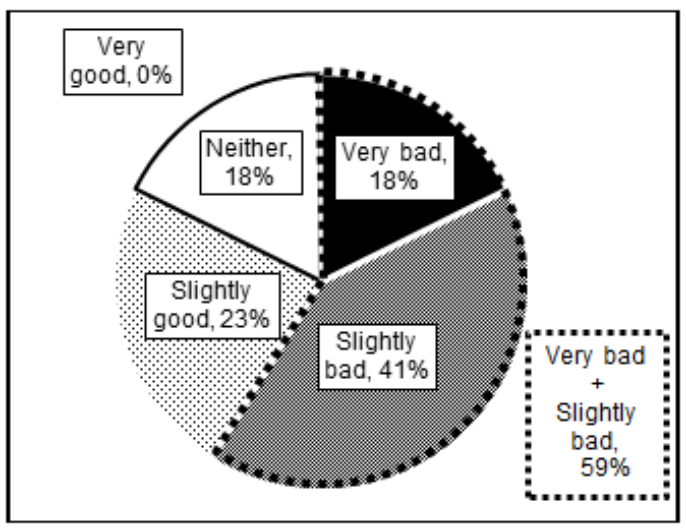

FIGURE 9. Do you feel good or bad at English?

Note. The dotted line shows the total ratio of the subjects who felt not good at English.

On the other hand, as shown in Figure 10, the subjects answered the question which asked if the VR activity provided an enjoyable English learning experience. As for the result, $94 \%$ of them answered "strongly agree" or "agree".

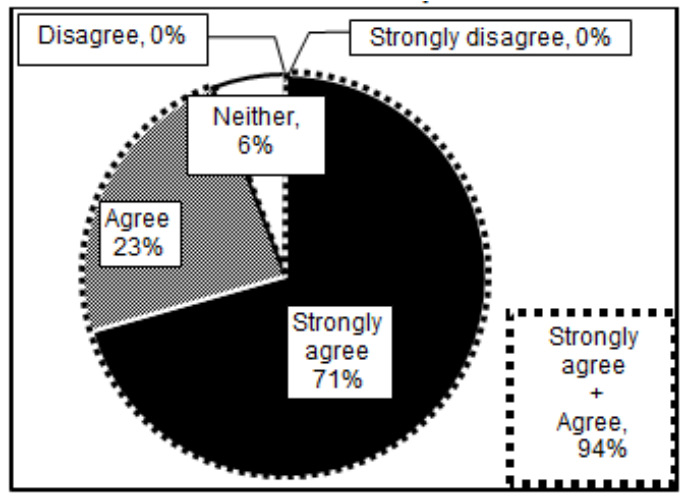

FIGURE 10. Do you agree that you can enjoy English learning using the VR-based activity? 
Note. The dotted line shows the total ratio of the subjects who could enjoy English learning.

Moreover, the result of these two questions revealed that all subjects who indicated they were "very bad" at English also answered they "strongly agree" with the statement "the VR activity can provide enjoyable English learning experience". In this test, almost all subjects had only a few experiences with VR in general and especially with handheld VR controllers. Table 5 shows the subjects' utilization experience of VR using VR peripherals. According to the data, nearly $50 \%$ of participants said they have used an HMD "once or twice". However, $71 \%$ of them said they have never used the VR controllers. It indicates they were using VR controllers for the first time during the treatment session.

TABLE 5. Have you ever used an HMD or VR Controllers?

\begin{tabular}{lll}
\hline \hline & HMD & VR Controllers \\
\hline Never & $29 \%$ & $71 \%$ \\
Once or twice & $47 \%$ & $23 \%$ \\
Three or four times & $18 \%$ & $0 \%$ \\
Five or six times & $6 \%$ & $6 \%$ \\
More than six times & $0 \%$ & $0 \%$ \\
\hline \hline
\end{tabular}

Figure 11 shows the subjects' answers to the question which asked if it was difficult to interact with the VR space using Oculus Quest's VR controllers. As a result, $41 \%$ of them answered "strongly disagree", and another $23 \%$ answered "disagree". Therefore, more than $60 \%$ of them answered it was not difficult although $71 \%$ of them were using the VR controllers for the first time during the test.

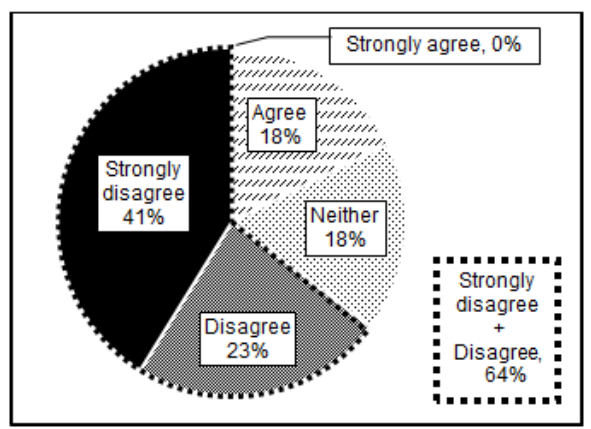

FIGURE 11. Do you agree that it was difficult to interact with the VR space using Oculus Quest's VR controllers?

Note. The dotted line shows the total ratio of the subjects who answered it was not difficult to use VR controllers. In addition, according to the subjects' answers to the question which asked if one would like to keep using the VR-based activity to study English, 29\% of them answered "strongly agree", and another 53\% answered "agree". Within the context of the current study more than $80 \%$ of them thought "I would like to keep using the VR application to study English".

The Analysis of Working Prototype Test: The Results from Two Simultaneous Videos

The gameplay videos showed that the subjects had one particular common behavior. When they were trying to put a word in an answer field in Q1, particularly during their first attempt, 13 subjects needed several times to successfully fix the word to the answer field. The videos which recorded subject's behavior in real space also showed that some of them asked the examiner how to fix a word to an answer field although they were told how to do it verbally before starting the activity. However, once they succeeded to drop the first word, they could manipulate the rest of words more smoothly during the treatment.

\section{DISCUSSION AND CONCLUSION}

Discussion in Terms of Japanese students' attitudes towards Learning English

In this study of 17 university students in Japan, more than half of the students felt they were not good at English. This was the case even though in Japan's university education system, English is a compulsory subject from Junior High School until the students become second-year university students. The results above are like those found by (Benesse Educational Research and Development Institute, 2018). It seems that the attitudes of language learners in Japan toward English communication are not easily changed by their extensive educational training, and they need to put more effort on studying English if they want to improve their English proficiency level.

\section{Discussion in Terms of the VR-based English Learning Activity}

Based on this study, the VR-based leaning activity is an effective way to provide an enjoyable way to study sentence word order, and to help to keep studying English grammar. This builds on the work by Heift (2003) through the inclusion of physical interactions during sentence word order tasks. In addition, the students have positive attitudes towards the activity. In fact, one of the subjects said "It was 
a new feeling to study English in the VR space room", and also said "the advantages of this activity were to use physical body action during the activity and to get various kinds of information from the whole VR space". These positive experiences and the potential to develop social bonds outside of the VR space add to the literature into TEL, in ways similar to Pardo-Ballester (2019). However, there are several important points that need to be considered prior to large scale deployment:

1) Some students felt virtual sickness during the activity

2) VR controllers are not familiar to most people

3) VR headsets may be too heavy to use for long periods of time.

Firstly, out of all the participants, there was only one student who answered, "Neither agree nor disagree" to the question "Do you agree that you can enjoy English learning using the VR-based activity?" In another question which asked about virtual sickness caused by the activity, the student said, "slightly felt virtual sickness" and another four students answered the same. It indicated that researchers (and language teachers) need to find ways to prevent virtual sickness before deploying VR application, or the users will never use the application even when it provides new, unique, and enjoyable experiences. Secondly, VR controllers are unfamiliar to most people. The controllers have unique shape and they are used instead of users' actual hands to interact with VR spaces. Therefore, the users are required to understand how to use the controllers before using VR application. While this is currently the case, recent advances may soon allow participants to interact in the VR space while using their actual hands, which may alleviate some issues related to the UI. With the above in mind, VR applications leverage the five human senses so that the experiences in VR space are difficult to explain without allowing participants to enter the actual VR experience. The users need to learn how to use the controllers and their behaviors in VR space during some form of preparatory training. Lastly, VR headsets may be too heavy for extended usage. To use a VR application, the users are required to keep wearing an HMD during the application. In the test, the weight of Oculus Quest's HMD is $\mathbf{5 7 1}$ grams and the average time to complete the five sentences is about 13 minutes. To make a comfortable VR experience, researchers should think about how long it takes to complete each task and the whole activity. This process should begin during the design of the application and continue through pilot testing.

\section{LIMITATIONS AND RECOMMENDATIONS}

The VR activity described here has the following limitations: a) The sentences for the activity must consist of six words.

b) There is no "skip" function or a "review" function.

c) There is no function to explain how to use the VR controllers.

d) Perhaps most importantly, the working prototype test did not include repeated measures of the subjects' English proficiency to examine any changes to language proficiency. Regarding the first limitation, the method for recording the subject' behaviors in real space needs some improvements. Firstly, the CSV file for loading sentences in the activity was formatted by the researcher, and the five sentences must be consisted of six words. Secondly, each activity cannot be skipped and will not show the answer even if the user's answer is wrong. Thirdly, the current system didn't have a function to explain how to use the controllers and how to complete the activity with them. Therefore, the lead researcher explained them verbally before starting the activity. Lastly, we didn't collect data about the subjects' English level and didn't perform any test before the working prototype test, so the five sentences we chose may not be appropriate for their English level and there was a lack of consideration to compare the impact of a paper-based or VRbased word order activity. Regarding recording the subjects' behaviors, the researchers recorded their full-body movements. However, to analyze the impact of the UI design, we need to record the specific gestures they made with their hands and fingers' when using the VR controllers.

The current study is part of a multiyear research grant. The VR activity described he will be used in a larger study that will attend to the limitations noted above, including:

a) A future study should better consider participants' English level when deciding the sample sentences. For instance, a researcher collects quotes from subjects' study abroad experiences or draws on a corpus data set to ensure the sentences reflect natural language usage.

b) As with other studies in the literature, an upcoming study will compare the differences among paper-based word order activity, computer-based (i.e. drag-and-drop) and a VRbased word order activity, to examine the effectiveness of each on improving the users' motivation. It's important to prove more clearly that the VR-based activity can provide an enjoyable learning experience over a longer period (e.g., several months).

c) A study to use the VR-based word order activity in an actual English language classroom, in both English as a Foreign Language (EFL) and an English as a Second Language (ESL) settings. The study could reveal the impact of VR- 
based activity for the users' standardized English test scores and oral proficiency as measured by holistic rubrics.

\section{ACKNOWLEDGEMENT}

This work was supported by JSPS KAKENHI Grant Number 19K00890.

\section{REFERENCES}

Beijing Bluefocus E-Commerce. (2016). A case study: The impact of VR on academic performance. Retrieved from https:// bit.ly/3doVMfP

Benesse Educational Research and Development Institute. (2018). Daijyesutoban tyuusansei no eigogakusyuu ni kansuru Tyousa: 2015-2018 Keizoku Kenkyuu. Retrieved from https://bit.1y/2BpMYs3

Education First. (2019). EF EPI, EF english proficiency index: A ranking of 100 countries and regions by english skills. Retrieved from https://bit.1y/3cq2Rva

Heift, T. (2003). Drag or type, but don't click: A study on the effectiveness of different CALL exercise types. Canadian Journal of Applied Linguistics, 6(1), 69-85.

Junnak, C., \& Veerachaisantikul, A. (2016). Reporting verb in research projects of EFL English major students. Journal of Advanced Research in Social Sciences and Humanities, 1(1), 41-46. doi:https://doi.org/10.26500/jarssh-01-2016 $-0105$

Ministory of Education, Culture, Sports, Science and Technology. (2014). Manabi no inobesyon jigyou jissyou kenkyuu houkokusyo, dainisyou syougakkou tyuugakkou ni okeru torikumi. Retrieved from https://bit. ly/36YXqCE

Ministry of Education, Culture, Sports, Science and Technology. (2013). The second basic plan for the promotion of education. Retrieved from https://bit. ly/36Q6HwC

Nakano, A. H. B., \& Wright, D. (2019). The construction of a virtual reality-based english language learning environment. In Paper presented at The Asia Pacific Conference on Enginnering and Natural Science, Bangkok, Thailand.

Pardo-Ballester, C. (2019). Technology-mediated TBLT in a hybrid environment: Bridging content and language production. Applied Language Learning, 29(1-2), 73-80.

Taher, M. A., Shrestha, P. N., Rahman, M. M., \& Khalid, A. K. M. I. (2016). Curriculum Linked Video (CLV) as a tool for English Language Teaching (ELT) at secondary school classrooms in Bangladesh. International Journal of Humanities, Arts and Social Sciences, 2(4), 126-132. doi:https://doi.org/10.20469/ijhss.2.20002-4

The Institute for International Business Communication. (2019). Eigogakusyuu no jittai to iyoku ni kansuru Tyousa Kekka. Retrieved from https://bit.ly/2AvsbTz

Thiangthung, Y. (2016). Applying Polya's four-steps and schoenfeld's behavior categories to enhance students' mathematical problem solving. Journal of Advances in Humanities and Social Sciences, 2(5), 261-268. doi:https://doi.org/10.20474/ jahss-2.5.2 